\title{
A brief history of inhaled asthma therapy over the last fifty years
}

\section{Graham Crompton}

\author{
14 Midmar Drive, Edinburgh EH10 6BU, United Kingdom
}

Received 26 September 2006; accepted 30 September 2006

KEYWORDS
Inhaled therapy;
Short-acting
beta-agonists;
Cromoglycate;
Inhaled corticosteroids;
Long acting
beta-agonists;
Pressuriced
metertd-dosf inna er

\section{KEYWORDS}

Inhaled therapy;

Short-acting

beta-agonists;

Cromoglycate;

Inhaled corticosteroids;

Long acting

beta-agonists;

metered-duss inna er

\begin{abstract}
Summary This year is the $50^{\text {th }}$ anniversary of the introduction into clinical use of the first modern inhaler for the management of asthma - the pressurised metereddose inhaler (pMDI). The pMDI was initially used for the administration of the non-selective beta-agonists adrenaline and isoprenaline. Howe er, the epidemic of asthma deaths which occurred in the 1960 s led to these urugs being superseded by the selective short-acting hieta-ayonist salbutamol, and the first inhaled corticosteroid (IC S) bee? nethasone. At the sams time, sodium cromoglycate was introdved, to be administered via thl f fir $t \mathrm{t} d \mathrm{r}$, oo wder inhaler - the Spinhaler - but oveng to its relatively werin ar ti. nfirnnatory action its use is now very limited. Over the last 10 year's the long-acting beta-agonists (LABAs) have become an important acid-or herapy for the management of asthma, and they are now often used with IE's in a single ICS/LABA combination inhaler.

(c) 2006 General Practice Airways Group. Published by Elsevier Ltd. All rights reserved.
\end{abstract}

\section{Contents}

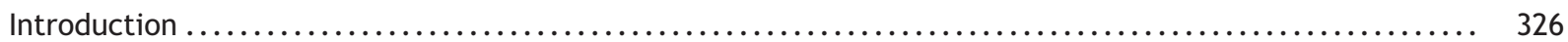

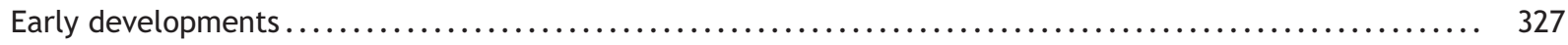

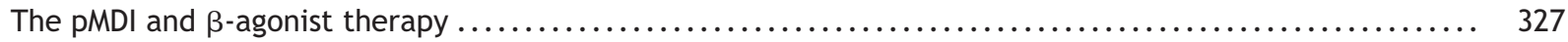

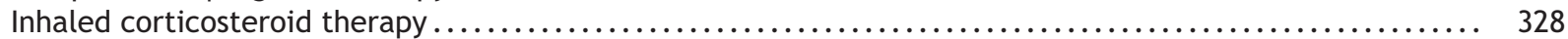

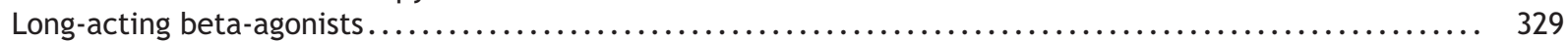

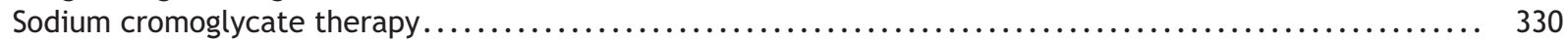

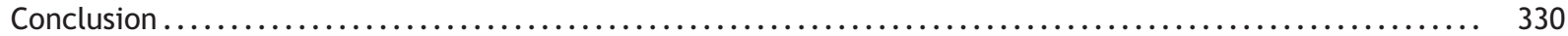

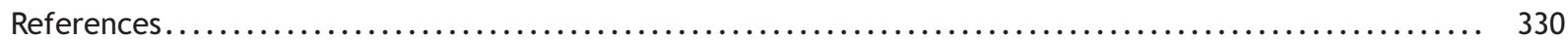

\section{Introduction}

Inhaled therapy is so fundamental to our modern management of asthma that it is difficult to

E-mail address: gkcromp@hotmail.co.uk. conceive of a time when asthma was managed without it. Yet the development of inhaled therapy 
for asthma epitomises the rapid pace of change in medical technology which occurred during the second half of the last century. Inhaled therapy, particularly inhaled corticosteroids (ICS), is the cornerstone of asthma treatment [1-3]. This short review outlines the development of inhaled asthma therapy during the fifty years after the introduction of the first pressurised metered-dose inhaler (pMDI) in 1956.

\section{Early developments}

Historically, the evolution of inhalation therapy can be traced to India as far back as 4000 years ago. However, the antecedents of contemporary inhalation therapy began in the nineteenth century with the invention of the hand-held glass bulb nebuliser. The first report of bronchodilator therapy being of benefit in asthma was by James Burnett, an Edinburgh physician, in 1903 [4]. However, inhalation therapy was revolutionised by the invention of the pMDI in the 1950s and its early introduction into clinical practice in 1956. The idea for the pMDI originated with George Maison, a medical consultant at Riker Laboratories (3M Pharmaceuticals) after seeing his daughter's difficulties using a hand bulb nebuliser. It is sáia that the time taken from concept to clinical' (S) Wils less than two years; interlatingly, oday research and developmen $\mathrm{pe}$ ip d would probably be in the region of wo decades.

\section{The pMDI and $\beta$-agonist therapy}

The pMDI soon became commercially successful because, for the first time, it provided a convenient method of delivering effective bronchodilator therapy. The rapid response to inhaled aerosols of the non-selective beta-agonists adrenaline and isoprenaline was much appreciated by asthmatic patients who could obtain the inhalers on prescription but who could also, for a period of time, buy the inhalers themselves 'over the counter' without a prescription. The most popular pMDI contained isoprenaline, and the prescription and sales of these inhalers rose by $600 \%$ between 1959 and 1965.

However, the satisfaction and faith in the efficacy of the isoprenaline pMDI, in part at least, contributed to the disastrous increase in asthma deaths in England and Wales coincident with the increase in sales of the isoprenaline pMDI during the 1960s [5,6]. There was much debate about the possible causes of the nearly
$400 \%$ increase in deaths from asthma in the 5-34 year age group, which, in view of the patients' ages, were unlikely to be caused by anything other than the disease itself or its treatment. This therefore constituted an 'epidemic' of asthma deaths of unknown cause. Isoprenaline toxicity was considered by most observers to be the most likely cause, although adverse reactions to the pressurised aerosol propellants were considered (and then excluded). An alternative to drug toxicity was postulated based on many asthmatic patients' reliance on the pMDI because of its reliever effect on symptoms of wheeze and breathlessness; it was thought that this could result in patients using the inhaler repeatedly in the anticipation that it would give relief eventually, thus leading to fatal delay in seeking medical advice at an early stage of a severe asthma attack. Of course this would also have resulted in excessive amounts of isoprenaline being inhaled, thus also making drug toxicity more likely. It had been demonstrated years previously that there is a decreasing response to inhaled bronchodilator therapy as asthma increases in severity, and the consequences of too much reliance on the efficacy of a bronchodilatcr inhaler as sole treatment of severe acite astnmia should, therefors $h: \epsilon$ beth predicted [7].

(iil 103 s the UK Coinmittee on the Safety of Medicines r $C$ S $/$ in is is d a warning to all clinicians in the lJo.hat excessive use of isoprenaline pMDIs could be dangerous. Following this, the sales of pMDIs decreased dramatically and the death rate from asthma returned to pre-epidemic levels [6]. This was taken as strong evidence that the toxic effects of isoprenaline were indeed the cause of the epidemic, but this was never proved. Although the fall in asthma death rate and the decrease in use of isoprenaline inhalers following the 1966 CSM warning appeared to confirm and support the view of many clinicians that isoprenaline pMDIs were indeed dangerous, there could have been other contributory explanations for the rapid fall in asthma mortality. Following the CSM alert there was a $100 \%$ increase in the number of patients with asthma admitted to hospital during the year after the warning [8] and there was also a significant increase in the national prescription of corticosteroids [9]. Early use of systemic steroids and admission to hospital are, of course, the two most important events in the successful management of the patient with life-threatening asthma. It is possible, therefore, that the CSM warning, because it reminded all clinicians that severe asthma is a potentially fatal condition, stimulated better management of their patients with regard to early hospital admission, and that 
this and the increased use of systemic steroids after the warning was at least a partial explanation of the fall in death rate rather than just the decrease in use of isoprenaline inhalers [10].

At Last...

UNIFORM DOSAGE NEBULIZATION in Asthma

\section{MEDIHALER}

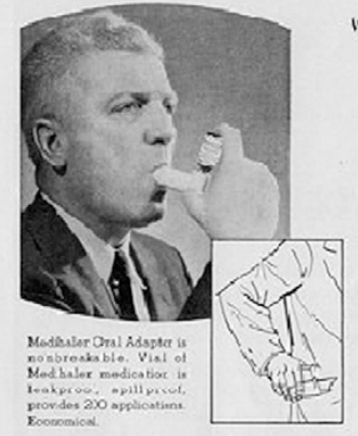

* MEDIHALER-EPI TN * MEDIHALER-ISO

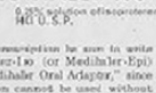

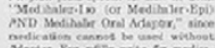

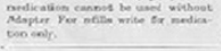

An early advertisemen io the nedihaler. Picture cour'esy of $W N$. inhalatorium .com

The major positive lasting efrect of the debate about the 1960s UK asthma epidemic was the widespread clinical recognition that diminishing response to an inhaled bronchodilator drug must be interpreted, by patients and clinicians alike, as heralding the onset of a severe asthma attack, and that more appropriate action must be taken other than simply using a bronchodilator inhaler more frequently. The major negative effect, however, was that both clinicians and patients considered pMDIs to be dangerous, and the fear of these devices was made somewhat worse when inhaled steroid therapy became available. It took more than a decade to overcome the fear associated with "steroids" and the pMDI.

The salbutamol pMDI was first marketed at a time when isoprenaline was thought to have been responsible for the British asthma deaths 'epidemic' and because of its more selective action on bronchial smooth muscle and reduced cardiac effects it soon replaced isoprenaline in the market; today, it remains the most frequently prescribed short-acting beta-agonist (SABA). Fears about SABA safety, however, were acutely rekindled by a publication which suggested a link between fenoterol, a 'selective' SABA but with slightly less $\beta_{2}$ selectivity than salbutamol, and a rise in asthma mortality in New Zealand [11]. This publication had been preceded by reports which suggested that SABA therapy could cause an increase in airway responsiveness in asthmatic patients $[12,13]$. These reports caused concern because of the obvious parallels with the debate about the 1960s UK asthma epidemic and even more concern was generated by the publication of the Sears paper in 1990 [14]. The debate about whether fenoterol or beta-agonists as a class were potentially dangerous in severe asthma continued [15-17], and the opinion of the respiratory community was split. In the end, regular treatment with beta-agonists was, in the main, replaced by 'as required' or 'as necessary' use. The debate continued for many years and regular treatment with salbutamol was only given a reasonably clean bill of health in 2000 [18]. However, the debate appears to have been rekindled recently, but today's focus of attention is on the long-acting beta-agonists (LABAs).

\section{Inhaled corticostereid trefapy}

Gucocorticosteroid (steroid) therapy is the most effective treatine. presently available for asthma [1-3]. Contisone, initially called Compound E, was extracted from the adrenal cortex by Edward Kendal at the Mayo Clinic in 1936. In 1950 the successful use of cortisone in asthma was first reported [19] and controlled clinical trial confirmation of its efficacy came in 1956 [20]. Within a few years of the first reports of the efficacy of systemic steroid therapy in asthma, prednisolone and hydrocortisone were synthesised and introduced into clinical practice. It soon became apparent, however, that longterm systemic steroid therapy, unless in very low dose, was associated with serious adverse effects including hypertension, osteoporosis, diabetes, obesity, facial mooning, acne, skin thinning and bruising. Research into safer administration of steroids led to the development and introduction into clinical practice of inhaled beclomethasone dipropionate (BDP) in the early 1970s. Initial reports of uncontrolled studies were enthusiastic [21-23] and placebo controlled studies soon confirmed the great value of this form of therapy [24-26].

There can be no doubt that the introduction of inhaled steroid therapy revolutionised the management of patients with chronic asthma, although in the early years, therapy was principally initiated by the hospital physician because of the 
great fear of steroid side effects created in the minds of general practitioners (GPs) by the use of systemic steroids for asthma and other diseases.

The first clinical trials of BDP and other inhaled steroids used a dosage regime of four times daily. For BDP the dose was $100 \mu \mathrm{g}$ four times daily using an inhaler that delivered $50 \mu \mathrm{g}$ per inhaler actuation ( 2 puffs four times daily). The fourtimes-daily administration frequency for inhaled steroid treatment became accepted as standard, even though this schedule was simply chosen empirically for the initial clinical trials. It soon became apparent to those clinicians supervising the management of large numbers of asthmatic patients that compliance with a four times daily dosing schedule was found to be difficult by a large number of patients. Three times daily BDP $(150 \mu \mathrm{g}$ three times daily) or twice daily treatment $(200 \mu \mathrm{g}$ twice daily) regimens were adopted and it soon became apparent that patients much preferred twice-daily treatment. This regimen was shown to be as effective as four-times-daily therapy using budesonide [27] and thereafter twice-daily treatment was increasingly used and later became the standard regimen for other inhaled steroids.

Although the introduction of BDP in the 1970s was a major advance in the treatment of asthma it quickly became apparent that a dose of $400 \mu \mathrm{g}$ a d $\mathrm{d} y$ was not sufficient to control symptoms of paients with severe chronic ast/fmct. In custuciy in 1975

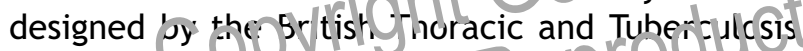
Association a mean dose of ahe 40 or m BDP was shown to be equivalent io 7 to $8 \mathrm{mg}$ of prednisolone in terms of asthma symptom control [28]. Therefore, those patients requiring $10 \mathrm{mg}$ or more prednisolone daily could not replace their systemic treatment with $400 \mu \mathrm{g}$ BDP daily. This led to larger doses of BDP being used, since it was assumed that adverse effects from steroids by the inhaled route would be less than those of oral prednisolone; this view was encouraged when it was reported that oral prednisolone could be withdrawn in many steroid-dependent patients already being treated with low dose BDP and prednisolone, if higher doses of BDP were used via a $250 \mu \mathrm{g}$ per actuation inhaler [29]. However, another study published in 1983, performed by the same group at the Royal Brompton Hospital, investigated patients taking long term high dose inhaled BDP and found evidence of adrenal suppression in those taking more than $1.5 \mathrm{mg}$ of BDP daily [30]. Treatment with high dose inhaled steroids became commonplace in the late 1980s and 1990s even though efficacy of high dose therapy was disappointing and it was shown that increasing the dose of BDP above $400 \mu \mathrm{g}$ had little or no extra clinical benefit $[31,32]$. There is, of course, abundant evidence now available that no clinical benefit is achieved, in the vast majority of cases, by increasing the dose of BDP or budesonide above $4-800 \mathrm{mcg}$ daily or fluticasone above $2-400 \mathrm{mcg}$ per day.

\section{Long-acting beta-agonists}

Salmeterol, the first long-acting beta-agonist (LABA), was introduced into clinical practice in the late $1980 \mathrm{~s}$ and great interest was generated by the first description of its clinical effects [33]. When it was first launched into clinical practice it was claimed to have clinically significant anti-inflammatory effects [34] as well as having a long bronchodilator action of up to twelve hours. Whether salmeterol had anti-inflammatory properties of clinical significance stimulated vigorous debate and this resulted in withdrawal of this claim from promotional literature in most countries. Also, the initial reaction of many clinicians to the concept of long-acting bronchodilatation was one of concern about safety. It was felt that if short actiris bela-agonists had been incriminated is the cause of death in some astinlic palients and in increasing Ponchial reactivity in others, then long-acting drugs of the sarne class could carry the added ri-k of longer-acting adverse effects. There was also concern that with salmeterol use there was the potential for an increase in the severity of breakthrough episodes of asthma. The fear was that the prolonged bronchodilator activity of salmeterol could potentially conceal an underlying worsening of the inflammatory condition, and that, if triggered by an allergen or other insult, a more severe episode of asthma could be the result. It was assumed that the allergen load or any other form of bronchial insult would have to be of greater magnitude to overcome the bronchodilatation of a long-acting beta-agonist (LABA) compared with a SABA and therefore the resulting breakthrough of asthma symptoms could be more severe. The author's concerns were expressed in a letter to the British Medical Journal in 1993 [35].

In 1994 concerns about salmeterol were somewhat assuaged when it was reported that adding salmeterol to the therapy of patients with poorly controlled asthma was better than increasing the dose of inhaled steroid [36]. The results of this study clearly showed that there was an unexpected benefit to be gained from adding salmeterol to treatment with steroids in terms of symptoms and PEF values. This study did not address the question of whether breakthrough 
exacerbations may be more frequent or more severe with regular salmeterol therapy. A study of similar design using different doses of salmeterol in patients with more severe disease was slightly reassuring, since patients with more severe asthma had been studied and exacerbation rates were similar. However, the study had also not been designed to assess severity of the exacerbations [37]. Following publication of a study specifically designed to assess the number and severity of exacerbation rates during treatment with the LABA formoterol and the inhaled steroid budesonide (BUD) [38], there was much greater reassurance, since the authors of this study concluded that the addition of formoterol to BUD therapy improves symptoms and lung function (confirming the earlier studies) without lessening control of asthma.

Finally, the sceptics (including the author) were persuaded that the combination of an LABA and an inhaled steroid is an effective and safe therapy when it was shown that the improvement in symptoms and exacerbations of asthma occurs without masking an undesirable effect on bronchial inflammation [39]. Combined therapy with an LABA and a steroid has become standard therapy for patients whose asthma symptoms are not adequately controlled by low-dose inhaled steroid alone, and this treatment has to be accepted) as a major advance in asthma therapv There renlain justifiable concerns resalding to inappropriate

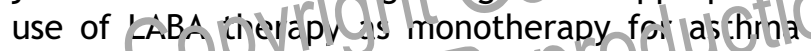
patients However, a recen renew has confirmed that, if used properly as acid-on therapy with inhaled steroids, LABAs are safe and effective [40].

\section{Sodium cromoglycate therapy}

Sodium cromoglycate (SCG) was introduced into clinical practice following the publication of a small clinical trial in 1967 [41]. Its mode of clinical action was thought to be due to mast cell stabilisation, but this was never established or fully understood. It was initially inhaled as a powder from a capsule via the Spinhaler (the first dry powder inhaler to be developed for asthma) because the amount of drug considered necessary to produce any clinical effect was too large to be delivered by the pMDI valve mechanisms available at that time. The initial promise of this very safe form of treatment was never fulfilled, but it was widely prescribed, perhaps mainly because of its safety profile. When the results of good mid- to long-term clinical trials in adults became available - such as the Medical Research Council trial in 1972 [42] showing that the efficacy of SCG was only equal to or less than that of low dose inhaled steroid therapy - the use of SCG gradually became almost completely confined to the treatment of children, especially those with exercise-induced asthma. Eventually, paediatricians almost abandoned its use, and the role of SCG in the treatment of asthma can now be summarised as "very limited" [43].

\section{Conclusion}

This brief review has highlighted the development of different sorts of inhaled therapy for asthma over the last 50 years, following the introduction of the pMDI in 1956. The early non-selective beta-agonists adrenaline and isoprenaline were quickly superseded by the selective short-acting beta-agonist (SABA) salbutamol and inhaled corticosteroids (ICS) in the early 1970s; treatment with ICS and as-needed SABAs is still the cornerstone of asthma management today. Sodium cromoglycate became available as a dry-powder inhaler in the late 1960s, but its fairly weak antiinflammatory action means that its use is now very limited. The advent of long-acting hata-agonists (LABAs) followed in the 1990; (thes: drugs can now safely be uspid in ombination with ICS for the darasenent of asthma.

\section{References}

[1] Global Strategy for Asthma Management and Prevention (GINA). NIH Publication No 02-3659. 2004.

[2] Van der Molen T, Ostrem A, Stallberg B, Stubbe Ostergaard $M$, Singh RB. International Primary Care Respiratory Group (IPCRG) Guidelines: Management of Asthma. Prim Care Resp J 2006;15(1):35-47.

[3] British Guideline on the Management of Asthma. BTS/SIGN. Thorax 2003;58: suppl 1.

[4] Burnett J. Adrenalin: A Short Account of its Therapeutic Applications. The Medical Times and Hospital Gazette. 1903; June 20th:385-87.

[5] Speizer FE, Doll R, Heaf P, Strang LB. Investigation into use of drugs preceding deaths from asthma. $\mathrm{Br}$ Med $\mathrm{J}$ 1968;1:339.

[6] Inman WH, Adelstein AM. Rise and fall of asthma mortality in England and Wales in relation to use of pressurised aerosols. Lancet 1969;2:279.

[7] Hume KM, Gandevia B. Forced expiratory volume before and after isoprenaline. Thorax 1957;12:279.

[8] Lyons HA, Ayres SM, Dworetzky M, et al. Symposium on isoproterenol therapy in asthma. Ann Allergy 1973;31:1.

[9] Inman WH. Recognition of unwanted drug effects with special reference to pressurised bronchodilator aerosols. In: Burley DM, Clarke SW, Cuthbert MF, Paterson JW, Shelley $\mathrm{JH}$, editors. Evaluation of bronchodilator drugs: an Asthma Research Council Symposium held at the Royal College of Physicians October 1973, 191. London: The Trust for Education and Research in Therapeutics; 1974. p. 200.

[10] Crompton GK. Metered dose inhalers - misuse. In: Epstein SW, ed. Metered Dose Inhalers. Proceedings of an 
international workshop held October 17-18, 1983. Mont Ste Marie, Quebec. ISBN 0-920163-01-7.

[11] Crane J, Pearce N, Flatt A, et al. Prescribed fenoterol and death from asthma 1981-83. Case controlled study. Lancet 1989;1:917.

[12] Kraan J, Koëter GH, van de Mark TW, et al. Changes in bronchial hyperreactivity induced by 4 weeks treatment with antiasthmatic drugs in patients with allergic asthma: A comparison between budesonide and terbutaline. J Allergy Clin Immunol 1985;76:628.

[13] Vathenen AS, Knox AJ, Higgins BG, Britton JR, Tattersfield $A E$. Rebound increase in bronchial responsiveness after treatment with inhaled terbutaline. Lancet 1988;1:554.

[14] Sears MR, Taylor DR, Print CG, et al. Regular inhaled beta-agonist treatment in bronchial asthma. Lancet 1990;336:1391.

[15] Spitzer WO, Suissa S, Ernst P, et al. The use of $\beta$-agonists and the risk of death and near death from asthma. N Eng J Med 1992;326:501.

[16] Van Schayck CP, Graafsma SJ, Visch MB, et al. Increased bronchial hyperresponsiveness after inhaling salbutamol during 1 year is not caused by subsensitization to salbutamol. J Allergy Clin Immunol 1990;86:793.

[17] Wong CS, Pavord ID, Williams J, Britton JR, Tattersfield AE. Bronchodilator, cardiovascular, and hypokalaemic effects of fenoterol, salbutamol, and terbutaline in asthma. Lancet 1990;336:1369.

[18] Dennis SM, Sharp SJ, Vickers MR, Frost CD, Crompton GK, Barnes PJ, Lee TH. Regular inhaled salbutamol and asthma control: the TRUST randomised trial. The Lancet 2000;355:1675-97.

[19] Carryer HM. The effect of cortisone on bronchial asthma and hay fever occurring in subjects insensitive to ragweod pollen. J Allergy 1950;21:282.

[20] Report to the Medical Research Colsil b; the Subcommittee on Clinica! 7 to $t$ in Asthma. Controlled trial of the eifects of corivole acetate in chronic asth na. Lancet $1956 \cdot 1$; $; \%$.

[21] Brown HM, Storey G, George vis. Beclomethasone dipropionate: A new steroid aerosol for the treatment of allergic asthma. Br Med J 1972;1:585.

[22] Chatterjee SS, Ross AE, Carol K, et al. Respiratory function in asthmatic patients using beclomethasone dipropionate administered by pressurised aerosol. Curr Med Res Opin 1972;1:173.

[23] Clark TJH. Effect of beclomethasone dipropionate delivered by aerosol in patients with asthma. Lancet 1972;1:1361.

[24] Cameron SJ, Cooper J, Crompton GK, Hoare MV, Grant IWB. Substitution of beclomethasone aerosol for oral prednisolone in the treatment of chronic asthma. $\mathrm{Br}$ Med J 1973;4:205.

[25] Hodson ME, Batten JC, Clarke SW, Gregg I. Beclomethasone dipropionate aerosol in asthma. Transfer of steroiddependent asthmatic patients from oral prednisolone to beclomethasone dipropionate aerosol. Am Rev Respir Dis 1974;110:403.

[26] Vilsvik JS, Schanning J. Beclomethasone dipropionate aerosol in adult steroid- dependent obstructive lung disease. Scand J Resp Dis 1974;55:169.
[27] Willey RF, Godden DJ, Carmichael J, Preston P, Frame M, Crompton GK. Comparison of twice daily administration of a new corticosteroid budesonide with beclomethasone dipropionate four times daily in the treatment of chronic asthma. Brit J Dis Chest 1982;76:61.

[28] British Thoracic and Tuberculosis Association. Inhaled corticosteroids compared with oral prednisolone in patients starting long-term corticosteroid therapy for asthma. Lancet 1975;2:7933.

[29] Smith MJ, Hodson ME. High-dose beclomethasone inhaler in the treatment of asthma. Lancet 1983;1:265.

[30] Smith MJ, Hodson ME. Effects of long term inhaled high dose beclomethasone dipropionate on adrenal function. Thorax 1983;38(9):676-81.

[31] Gaddie J, Petrie GR, Reid JW, Sinclair JDM, Palmer RNV. Aerosol beclomethasone dipropionate: a dose-response study in bronchial asthma. Lancet 1973;ii:280-1.

[32] Boe J, Rosenhall L, Alson M, et al. Comparison of doseresponse effects of inhaled beclomethasone dipropionate and budesonide in the management of asthma. Allergy 1989;44:349-55.

[33] Ullman A, Svedmyr N. Salmeterol, a new long acting inhaled $\beta_{2}$ adrenoreceptor agonist: comparison with salbutamol in adult asthmatic patients. Thorax 1988;43:674.

[34] Twentyman OP, Finnerty JP, Harris A, Palmer J, Holgate ST. Protection against allergen-induced asthma by salmeterol. Lancet 1990;336:1338.

[35] Crompton GK. Regular treatment with $\beta$ agonists remains unevaluated. Br Med J 1993;306:1610.

[36] Greening AP, Ind PW, Northfietd in Shallv G. Added salmeterol versus hisher.once coricosceroid in asthma patients w th y m tor or existing inhaled corticosteroid. Lace $994 ; 344: 219$.

1377] Woolcock A [undisach B, Ringdal $N$, Jacques LA. Comparis of of 1 ditiogn of Salmeterol to Inhaled Steroids $\sqrt{\text { iit }}$ Loubling the Dose of Inhaled Steroid. Am J Respir Crit Care Med 1996;153:1481.

[38] Pauwels RA, Löfdahl C-G, Postma DS, Tattersfield AE, et al. Effect of inhaled formoterol and budesonide on exacerbations of asthma. New Eng J Med 1997;337: 1405.

[39] Kips JC, O'Connor BJ, Inman MD, Svensson K, et al. A longterm Study of the Antiinflammatory Effect of Low-dose Budesonide Plus Formoterol versus High-dose Budesonide in Asthma. Am J Respir Crit Care Med 2000;161:996.

[40] Nelson HS. Long-Acting Beta-Agonists in adult Asthma: Evidence that these Drugs are Safe. Prim Care Resp J 2006;15(5):271-7.

[41] Howell JBL, Altounyan REC. A double-blind trial of disodium cromoglycate in the treatment of allergic bronchial asthma. Lancet 1976;ii:539.

[42] Brompton Hospital/Medical Research Council Collaborative Trial. Long-term study of disodium cromoglycate in the treatment of severe extrinsic or intrinsic bronchial asthma in adults. Br Med J 1972;4:383-8.

[43] Thomson NC. Other Therapies. Chapter 16 in Asthma and COPD. Basic Mechanisms and Clinical Management. In: Barnes PJ, Drazen JM, Rennard S, Thomson NC, editors. Academic Press, An Elsevier Science Imprint, London; 2002. 